\title{
CAPACIDADE PROPOSITIVA DAS OUVIDORIAS UNIVERSITÁRIAS: UM RELATO DE EXPERIÊNCIA DA OUVIDORIA FMUSP
}

Alice Abi-Eçab ${ }^{1}$

\begin{abstract}
Resumo
Este artigo propõe o debate sobre a importância de Ouvidorias universitárias buscarem compreender, de forma ampla, o contexto de possibilidades do modo de vida dos usuários de seu serviço, que pode ser entendido como uma função de competência das Ouvidorias que utilizam o processo de trabalho propositivo próprio das chamadas "Ouvidorias ativas". Questões como a qualidade de vida, o acesso à informação no território, a sustentabilidade do ambiente, a rede de serviços e a garantia de direitos dos usuários, enquanto pilares do entendimento integral aos direitos humanos, podem servir como instrumento para orientar o processo de gestão (planejamento, monitoramento, avaliação) de uma instituição de ensino superior por meio da colaboração das Ouvidorias universitárias. À luz de uma perspectiva interdisciplinar, sob a visão de totalidade e integralidade dos processos sociais, o artigo situa o leitor acerca da estrutura da Rede Apoio ao Estudante da FMUSP, na qual a Ouvidoria participa e agrega seu valor operacional, com independência hierárquica na estrutura do organograma institucional; e compartilha ideias como sugestão para a elaboração de um projeto de pesquisa, por parte de Ouvidorias universitárias, que capte a realidade vivida pelos estudantes, enquanto sujeitos de direitos, em sua relação de pertencimento e identificação com o ambiente universitário, com expectativas e oportunidades de vivências e experimentações, a partir desse território público, para a melhoria contínua dos serviços institucionais.
\end{abstract}

Palavras-chave: Ouvidoria universitária. Rede. Universidade de São Paulo.

DOI:10.37814/2594-5068.2020v3.p107-118

1 Ouvidora na Faculdade de Medicina da Universidade de São Paulo. Mestra em Serviço Social pela Pontifícia Universidade Católica de São Paulo. Especialista em Gestão Pública pela Universidade Federal de São Paulo. Professora em cursos de graduação e pós-graduação, possui experiência nas esferas estadual e municipal, atuando com políticas públicas e sociais. (alice.aecab@fm.usp.br.) (www.fm.usp.br/ouvidoria) (ouvidoria@fm.usp.br.) 


\begin{abstract}
This paper proposes the debate about the importance of university Ombudsmen to comprehend comprehensively the context of possibilities of the way of life of the users of their service, which can be understood as a function of the Ombudsman's competence that use the process of propositive work, the so-called "active Ombudsmen". Issues such as quality of life, access to information in the territory, sustainability of the environment, service network and the guarantee of users' rights, as pillars of the integral understanding of human rights, can serve as a tool to guide the management process (planning, monitoring, evaluation) of an institution of higher education through the collaboration of university Ombudsmen. In the light of an interdisciplinary perspective, under the vision of totality and integrality of social processes, the paper places the reader on the structure of the Student Support Network of FMUSP, in which the Ombudsman participates and adds its operational value, with hierarchical independence in the structure of the institutional organization chart; and shares ideas as a suggestion for the elaboration of a research project by university Ombudsmen that captures the reality lived by students, as subjects of rights, in their relation of belonging and identification with the university environment, with their expectations and opportunities of experience and experimentation, from this public territory, for the continuous improvement of institutional services.
\end{abstract}

Keywords: University Ombudsman. Network. University of São Paulo. 


\section{INTRODUÇÃO}

A construção do artigo "Capacidade propositiva das Ouvidorias universitárias: um relato de experiência da Ouvidoria FMUSP" possui como ponto de partida experiências profissionais da autora no ambiente da Universidade de São Paulo (USP), por meio da gestão da Ouvidoria da Faculdade de Medicina da Universidade de São Paulo (FMUSP), a qual integra a rede de serviços institucionais oferecidos nessa Casa. Elaborado por meio dessas experiências, o artigo também apresenta o compartilhamento de um esboço de projeto de pesquisa que propõe, como sugestão de investigação a ser feita por Ouvidorias universitárias, uma aproximação entre demanda e oferta de serviços, tendo como sujeitos os estudantes de graduação desse território universitário.

Além da atual experiência como Ouvidora, vale pontuar a atuação profissional anterior da autora como assistente social na própria USP, prática que gerou conhecimento aprofundado das demandas sociais, culturais, ambientais, esportivas, de lazer, de pesquisa e empregabilidade dos estudantes no interior do campus Butantã, na capital do Estado de São Paulo. Naquele momento, tais demandas dos estudantes sinalizavam uma busca pela oferta integral de serviços universitários, os quais por vezes não eram oferecidos pela Universidade ou oferecidos em quantidade não capaz de atender com excelência à procura da comunidade discente.

Com base nisso, para compreender de forma ampla o atual contexto de possibilidades do modo de vida universitário, que pode ser entendido como de competência das Ouvidorias universitárias no formato "Ouvidorias ativas" -, dividimos o desenvolvimento desse artigo em duas partes, quais sejam: i) situar o leitor acerca da estrutura da Rede Apoio ao Estudante da FMUSP, na qual a Ouvidoria participa e agrega seu valor operacional, com independência hierárquica na estrutura do organograma institucional; ii) o compartilhamento de ideias como sugestão para a elaboração de um projeto de pesquisa, por parte de Ouvidorias universitárias, que capte a realidade vivida pelos estudantes, enquanto sujeitos de direitos, em sua relação de pertencimento e identificação com o ambiente universitário, com expectativas e oportunidades de vivências e experimentações a partir desse território público.

Levantar questões como a qualidade de vida, o acesso à informação, a sustentabilidade do ambiente, a rede de serviços oferecida, com garantia e capacidade de acesso a direitos pelos usuários, enquanto pilares do entendimento integral de acesso a direitos, portanto competências próprias de Ouvidorias Públicas, podem servir como instrumento para orientar o processo de gestão (planejamento, monitoramento, avaliação) de uma instituição de ensino superior (IES), como é aqui tratado no artigo, assim como nos demais territórios assemelhados.

No projeto de pesquisa sugerido, é relevante discutir o processo histórico da questão social²,

2 "Nos anos de 1930, a economia brasileira gradualmente passa a modificar seu modo de produção por meio do processo urbano-industrial - do agrário-comercial para o industrial -, já que é no interior das relações de trabalho do operariado que se dá a contradição capital-trabalho. Esta tensão social de disputa (entre capital e trabalho) agrava a questão social, a qual pode ser entendida [em linhas breves] como o conjunto de problemas políticos, sociais e econômicos que despontam na relação conflituosa entre o mundo do trabalho e o modo capitalista de produção" (ABI-EÇAB, 2015, p. 12). O conceito de questão social pode ser aprofundado em MONTAÑO (2012), NETTO (2001) e SANTOS (2012). 
com suas expressões no cotidiano da sociedade, assim como dificuldades vividas pela comunidade de estudantes. Assim, poderá ser analisado um possível contexto contraditório no bojo de uma mesma arena social: de um lado a garantia de acesso a direitos assegurada pelas políticas; de outro, a agenda de corte de gastos gestada na realidade do capitalismo contemporâneo (NETTO e BRAZ, 2007).

Nesse panorama, é elementar a construção e o fortalecimento de ferramentas que possam aprimorar a trajetória da IES, no caso em tela da Universidade de São Paulo ${ }^{3}$, no que tange ao ambiente e serviços oferecidos à comunidade de estudantes. Assim, o enfoque na qualidade de vida e acesso a direitos - para dimensionar a concepção holística de ser humano como ser biopsicossocial - é indispensável para uma análise da dinâmica universitária sob uma perspectiva de totalidade e integralidade.

\section{INSERÇÃO DE OUVIDORIAS NA REDE INSTITUCIONAL DOS SERVIÇOS DE ATENDIMENTO}

Em âmbito público, Ouvidorias são canais de diálogo entre sociedade e Estado, com o objetivo de buscar melhorias contínuas nos processos institucionais e nos serviços oferecidos à população, atuando em prol da promoção da cidadania. Em parceria com a direção máxima da IES, para o aperfeiçoamento da gestão universitária e satisfação dos usuários de seus serviços, as Ouvidorias universitárias devem se apoiar nos pilares de sigilo à identidade, discrição, proteção à segurança dos dados e comprometimento ético. Com acolhimento ao manifestante e tratamento qualificado das demandas, incumbem-se de recepcionar, analisar, encaminhar e monitorar as manifestações até o seu encerramento.

Relevante ressaltar que o pleno funcionamento das Ouvidorias, tanto públicas quanto privadas, é fundamental para a gestão de qualidade dos processos de trabalho institucionais e para a governança corporativa da pessoa jurídica que as abriga. Considerando o leque de instrumentos operacionais que Ihes é de competência, as Ouvidorias utilizam-se - expressivamente - da comunicação com o usuário e com as áreas técnicas e administrativas para a mediação de conflitos e acompanhamento da resolução das demandas apresentadas. Nesse contexto, é a partir de um refinado sistema de gestão de manifestações e de captação e tratamento de dados que será possível para as Ouvidorias desenharem indicadores consistentes e fidedignos da realidade para uso da autoridade máxima institucional e para o empoderamento da população, em benefício coletivo, por meio da ampla divulgação pública desses dados.

Em consonância com o Código de Ética do Ouvidor/Ombudsman (ABO, 1997) ${ }^{4}$, a previsão é que Ouvidorias Públicas exerçam suas atividades com independência e autonomia funcional,

3 "Em mais um ranking, USP é considerada a melhor universidade brasileira. Classificação elaborada pela consultoria britânica Times Higher Education avalia instituições da América Latina" (Jornal da USP, 2019).

4 O Código de Ética do Ouvidor/Ombudsman prevê que Ouvidorias Públicas exerçam suas atividades com independência, resguardando o sigilo das informações e promovendo a justiça e a defesa dos interesses legítimos dos cidadãos. 
resguardando o sigilo das informações e promovendo a justiça e o acesso a direitos e interesses legítimos dos cidadãos. Assim, Ouvidorias têm a função fundamental de trabalhar para o aprofundamento do conceito do direito à cidadania e para o efetivo exercício e respeito desse direito pela sociedade e agentes públicos.

A seguir, preparamos um fluxo indicativo de algumas das principais funções que são de competência de Ouvidorias universitárias:

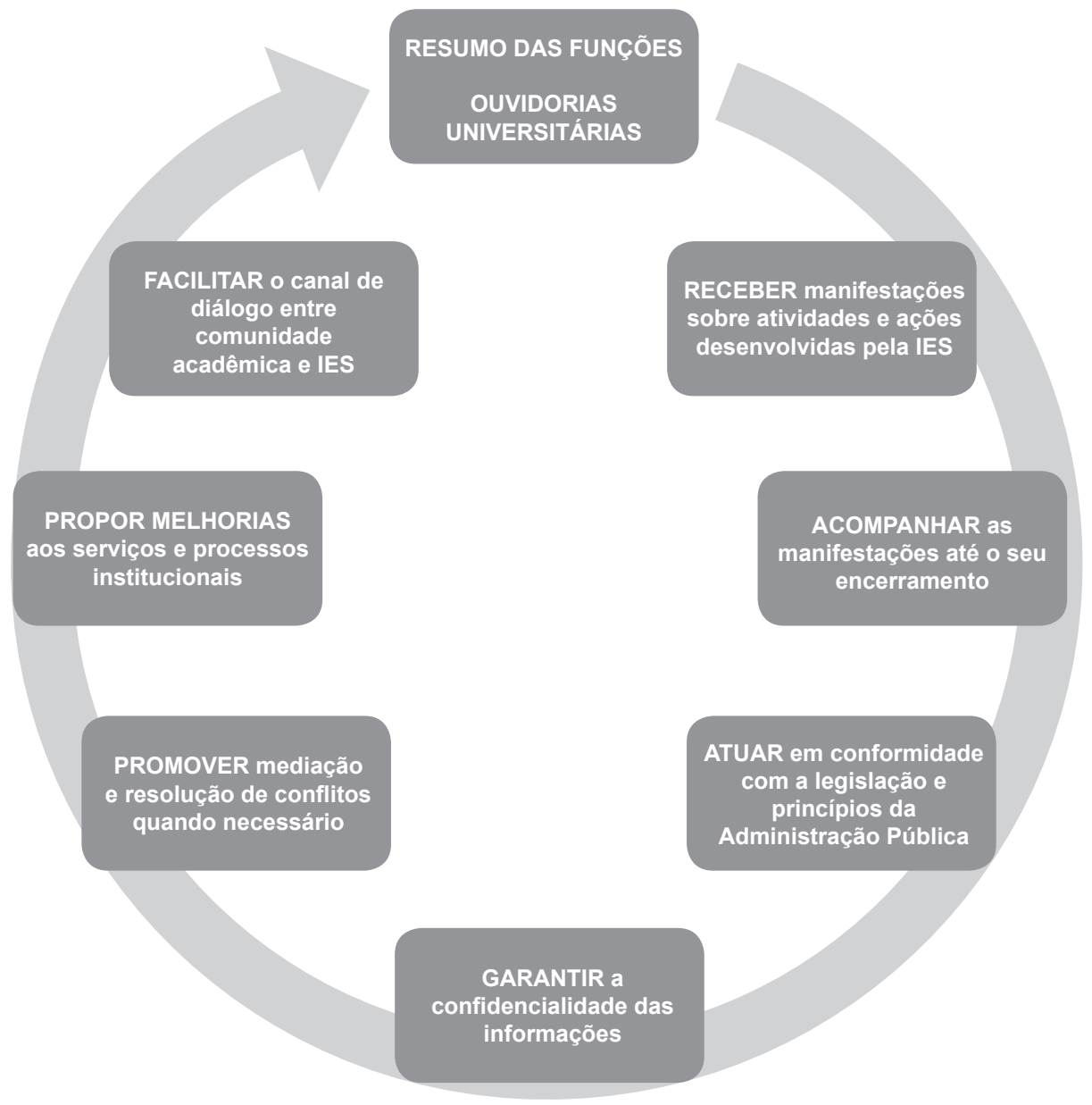

Fonte: elaboração da autora (2019)

Vale frisar que, segundo a literatura especializada, Ouvidoria Pública não deve ser compreendida como instância específica de defesa de direitos, pois não tem a competência de atuar como advocacia pública ou desenvolver ações de investigação, sindicância, judicação e punição. O foco das Ouvidorias Públicas é garantir um canal de diálogo direto entre população e Poder Público e contribuir para o livre acesso à informação, conforme legislação vigente.

Segundo apresentado no Guia de Orientação Para a Gestão de Ouvidorias (CGU, 2013, p. 9), a "Ouvidoria não é, assim, uma estrutura criada para defender direitos dos cidadãos, e sim para garantir meios para que os direitos dos cidadãos de serem ouvidos e de participarem da Adminis- 
tração Pública se efetivem". Nesse sentido, a Ouvidoria FMUSP ${ }^{5}$ está configurada como instância mediadora por excelência, operando com imparcialidade, caráter sigiloso e independência, sendo responsável por acolher demandas e buscar resolutividades entre as partes envolvidas, atuando como facilitadora desse diálogo entre cidadão e Estado.

No esforço de ampliar a rede de atendimento à comunidade acadêmica para a contínua meIhoria de seus índices de prestação dos serviços com excelência, a FMUSP articulou seus diversos equipamentos e serviços e criou a Rede Apoio ao Estudante da Faculdade de Medicina da USP, que engloba os seguintes cursos de graduação: Medicina, Fisioterapia, Fonoaudiologia e Terapia Ocupacional. O objetivo é oferecer suporte à comunidade acadêmica com informações sobre os espaços e serviços e programas institucionais. Abaixo, apresentaremos os quatro equipamentos que integram a Rede:

\section{- Ouvidoria}

Compromisso em oferecer um espaço democrático de controle e participação social, constituindo-se como canal aberto de comunicação com a comunidade acadêmica (colaboradores, estudantes, pesquisadores, professores, residentes e terceirizados). Como instância estratégica diretamente ligada à Diretoria, possui caráter mediador e imparcial, além de autonomia funcional no tratamento qualificado das manifestações recebidas. Colabora na construção de espaços plurais e abertos à negociação e na promoção do exercício da cidadania.

\section{- Núcleo de Apoio ao Estudante}

Apoio às necessidades socioeconômicas, acadêmico-pedagógicas, de saúde mental e de promoção da saúde de estudantes de graduação. Opera programas e ações contínuas de monitoramento e de atendimento. É composto pelos seguintes serviços:

- Acolhimento Integrado

- Serviço Social

- Serviço de Assistência em Saúde Mental

- Coordenação de Promoção de Saúde

- Coordenação e Tutoria Acadêmica

\section{- Núcleo de Ética e Direitos Humanos}

Apoio às políticas de ética e direitos humanos, cujas ações são direcionadas para a promoção de relações sustentáveis em relação às diversidades (sexual, gênero, raça e etnia, religião, condições socioeconômicas).

\section{- Centro de Desenvolvimento de Educação Médica}

Apoio à educação na área da saúde por meio de programas de desenvolvimento docente e pesquisa, constituindo frentes de trabalho com estudantes por meio do Programa de Mentoria e do

5 A Ouvidoria da Faculdade de Medicina da Universidade de São Paulo, com implantação datada de janeiro de 2015, foi criada para o tratamento de manifestações enviadas por sua comunidade acadêmica, e também pela sociedade em geral, no que se refere às atividades e ações desenvolvidas pela FMUSP. 
Suporte Pedagógico. É composto pelos seguintes serviços:

- Núcleo de Desenvolvimento Docente

- Núcleo de Pesquisa

- Núcleo de Avaliação

- Núcleo de Desenvolvimento Profissional.

Observamos que é fundamental que a estrutura da Ouvidoria esteja fixada no organograma institucional sem intermediários hierárquicos, reportando-se diretamente à alta direção, no caso, à Diretoria FMUSP. Tal condição é indispensável para justificar sua autonomia funcional, independência e compromisso com os interesses do usuário e da instituição. Abaixo, o organograma demonstra um posicionamento adequado para Ouvidorias:

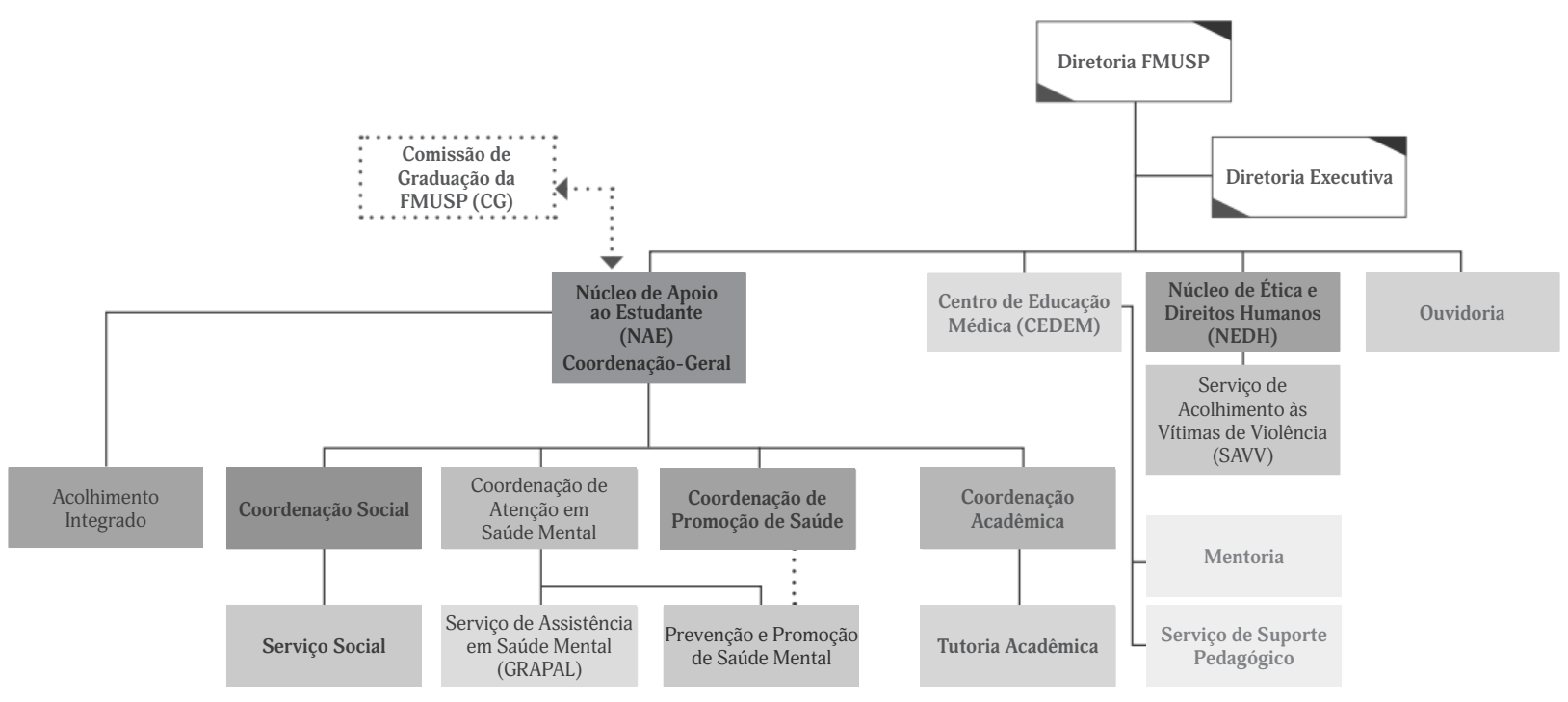

Fonte: Portal FMUSP (2019)

Nesse sentido, principalmente pela FMUSP estar situada na área da saúde, vale ressaltar o conceito amplamente aceito da Constituição da Organização Mundial da Saúde (OMS, 1946, [s.p.]), no qual a saúde é entendida como "um estado de completo bem-estar físico, mental e social e não somente a ausência de afeções e enfermidades". Esse é um direito a ser garantido ao cidadão. Analisando a saúde com o "foco na saúde da coletividade, a interdisciplinaridade e ações de promoção, prevenção e recuperação da saúde humana" (FORTES e RIBEIRO, 2014, [s.p.]) e agregando a fundamental contribuição da legislação nacional da política pública da saúde ${ }^{6}$, observa-se que o

6 Como principais marcos legais da saúde no Brasil, cita-se a Constituição Federal (artigos 196 a 200); a Lei 8.080/1990 - Lei Orgânica da Saúde (dispõe sobre as condições para a promoção, proteção e recuperação da saúde, a organização e o funcionamento dos serviços correspondentes e dá outras providências); e a Lei 8.142/1990 (dispõe sobre a participação da comunidade na gestão do Sistema Único de Saúde - SUS e sobre as transferências intergovernamentais de recursos financeiros na área da saúde e dá outras providências). Contudo, a efetivação da legislação não é absoluta e vale a reflexão de que "é indispensável, porém, que ela preveja mecanismos para que nenhum dos direitos afirmados seja negado na prática constitucional. Apenas a implantação responsável de um sistema de saúde com base municipal pode viabilizar a garantia do direito à saúde" (DALLARI, 1988, [s.p.]). 
acesso aos direitos deve ser compreendido em sentido amplo e contemplar, em seu significado, uma visão integral de atenção ao modo de vida dos sujeitos.

A partir dessas implantações e diante das reflexões e demandas do cotidiano, a Ouvidoria FMUSP pensou em um protótipo de projeto de pesquisa para o alcance de maior aprofundamento e aproximação aos sujeitos com os quais trabalha, assim como também com a rede institucional de serviços e equipamentos que integra. Decidimos, então, compartilhar tal projeto de pesquisa, o qual poderá ser útil para Ouvidorias universitárias, tanto públicas como privadas, para que - com as devidas adaptações às necessidades locais e institucionais de cada território -, possam utilizar os tópicos sugeridos a fim de nortear pesquisas com o objetivo de buscar melhorias contínuas e inovações em seus processos de trabalho, tornando-os objeto de uma gestão sustentável.

\section{SUGESTÃO PARA A ELABORAÇÃO DE PROJETO DE PESQUISA POR OUVIDORIAS UNIVERSITÁRIAS}

Com uma proposta de conteúdo crítico e transformador, a pesquisa deve utilizar um campo de atuação interdisciplinar e de interação entre as seguintes esferas: qualidade de vida, ambiente, sustentabilidade, acesso à informação e direitos, entre outras possíveis categorias. Englobando temas sociais, culturais, ambientais, esportivos, de lazer, de pesquisa e oportunidades de empregabilidade - tradicionalmente percebidos como demandas dos estudantes -, as complexidades e dinâmicas do território universitário e os rebatimentos dessas realidades na vida dos sujeitos devem ser percebidos e medidos para posterior intervenção institucional.

O propósito dessa sugestão para a elaboração de um projeto de pesquisa está em buscar uma aproximação com o modo de vida dos estudantes e suas demandas reais, identificando possíveis pontos de reflexão a serem discutidos no contexto da IES com relação ao nível de disponibilidade de diálogo que a instituição estabelece com sua comunidade de estudantes, usuária de bens e serviços disponibilizados no território universitário.

A pesquisa poderá, também, apresentar como proposta a construção de um banco de dados e conhecimentos relevantes para o planejamento da IES no atendimento às demandas da comunidade de estudantes, com ideias e possíveis respostas, identificando limites e desafios, mapeando necessidades objetivas e subjetivas dos sujeitos no contexto do território.

Por meio do manejo de ferramentas de pesquisa selecionadas e adequadas para o alcance dos objetivos, a intenção precípua do estudo é agregar forças na melhoria contínua e sustentável da qualidade de vida dos estudantes na IES, buscando organizar legitimidades a partir das demandas dos sujeitos, aprimorando as políticas universitárias já existentes, e construir novos paradigmas no atendimento integral das necessidades dos sujeitos.

A pesquisa deve ser concebida no sentido de propor um levantamento da atual situação de possibilidades de vivências dos estudantes na atual conjuntura de bens e equipamentos universitários oferecidos à comunidade de discentes. Em um segundo momento, a partir do conhecimento produzido, deverão ser empreendidas análises e discussões acerca da necessidade de criação e aprimoramento de políticas universitárias nas dimensões sugeridas pelo estudo (qualidade de vida, 
ambiente, sustentabilidade, acesso à informação e direitos).

A partir disso, poderão ser reunidos esforços para a criação de um conjunto de indicadores de bem-estar dos sujeitos inseridos no território (ou seja, dos estudantes no contexto do campus universitário), identificando e examinando os principais obstáculos e viabilidades para a inserção e melhoria de políticas comunitárias no cenário da IES.

Consoante à competência das Ouvidorias em atuar de forma propositiva, a pesquisa deve apresentar a intenção de ampliar o espaço de debate no assunto em pauta e proporcionar o aprofundamento na análise de indicadores e categorias que resultem em intervenções eficientes, eficazes e efetivas pelas áreas técnicas e administrativas, no bojo do ambiente que é oferecido aos estudantes, contribuindo para melhor qualidade de vida e acesso a direitos.

Podem ainda configurar como objetivos da pesquisa:

- Levantar dados das categorias propostas (demandas dos estudantes).

- Identificar as políticas universitárias, bens e equipamentos disponíveis.

- Examinar a atuação institucional diante das demandas da comunidade discente.

- Cruzar dados e informações levantando possíveis correlações.

- Refletir sobre a qualidade de vida como direito fundamental.

- Problematizar intenções da instituição e necessidades dos estudantes.

- Disponibilizar de forma pública e de fácil acesso, por meio da internet, as informações produzidas para o uso da IES e da comunidade acadêmica.

Acerca da metodologia e do plano de trabalho, à luz de uma perspectiva interdisciplinar e sob a visão de totalidade e integralidade dos processos sociais, a pesquisa poderá ser guiada por procedimentos metodológicos qualitativos e quantitativos.

A coleta das informações e dados deverá ser construída a partir de sucessivas aproximações com o objeto definido pelo estudo, utilizando pesquisa documental com dados primários (obtidos por pesquisa direta) e dados secundários (decorrentes de outras pesquisas já produzidas).

$\mathrm{Na}$ dimensão qualitativa, poderão ser propostas pesquisas bibliográficas e documentais, aliadas à aplicação de questionários online com perguntas abertas aos sujeitos participantes, examinando o significado das palavras, ideias e mensagens que despontarem nas manifestações dos participantes.

Na dimensão quantitativa, poderão ser utilizados questionários online com perguntas objetivas, observando a frequência com que são usadas determinadas palavras, ideias, valores ou mensagens por meio das respostas. O acúmulo teórico em estudos afins já realizados, além de produções bibliográficas e documentais, deverão embasar a pesquisa.

Por intermédio do exame detalhado dos dados colhidos, o próximo passo é localizar e estabelecer categorias analíticas para classificar os dados levantados, promovendo um estudo pormenorizado das manifestações localizadas nos levantamentos quali-quanti. Procedimentos como descrição, interpretação, compreensão e explicação dos significados apresentados no material coletado serão analisados e inseridos em um panorama crítico e interdisciplinar de totalidade e integralidade de saberes. 
A relevância e os resultados esperados da pesquisa estarão fixados na reunião de dados acerca das demandas dos estudantes e no levantamento da rede de serviços e equipamentos universitários oferecidos, construindo novos paradigmas e soluções sustentáveis para a IES no atendimento às necessidades da comunidade acadêmica, repensando e aprimorando o atual formato das políticas universitárias a partir das reais necessidades dos sujeitos que estão inseridos no território.

\section{CONSIDERAÇÕES}

Este artigo propôs o debate sobre a importância de que a Ouvidoria universitária busque compreender, de forma ampla, o contexto de possibilidades do modo de vida dos usuários de seu serviço, que pode ser entendido como de competência das Ouvidorias que utilizam o modo de trabalho propositivo das chamadas "Ouvidorias ativas".

O artigo esteve dividido na preocupação em situar o leitor acerca da estrutura da Rede Apoio ao Estudante da FMUSP, da qual a Ouvidoria participa e agrega seu valor operacional, com independência hierárquica na estrutura do organograma institucional; e no compartilhamento de ideias como sugestão para a elaboração de um projeto de pesquisa, por parte de Ouvidorias universitárias, que captasse a realidade vivida pelos estudantes, enquanto sujeitos de direitos, em sua relação de pertencimento e identificação com o ambiente universitário, com expectativas e oportunidades de vivências e experimentações a partir desse território público.

Assim, a Ouvidoria que vier a elaborar e executar a pesquisa deverá observar se há viabilidade de execução do projeto, visto que é necessário o mínimo de expertise profissional e acúmulo teórico-metodológico no campo temático em estudo. Além disso, também é relevante mencionar a contribuição interdisciplinar que a pesquisa buscará trazer para alargar e fortalecer a compreensão das demandas presentes na IES, com interface com as esferas da saúde integral, da sustentabilidade e dos direitos de cidadania. O bem-estar do estudante, enquanto cidadão e usuário de serviços públicos, colabora ativamente para a manutenção dos índices de excelência no ensino, pesquisa e extensão universitária da IES e na garantia e promoção do exercício da cidadania pelos usuários.

Outro ponto fundamental para discussão, como indicação para futuros estudos, é: como os atores institucionais podem fortalecer a rede de serviços de atendimento aos usuários? Ainda, como podem implantar canais de participação da população com sugestões e novas ideias para a melhoria dos serviços? E como os usuários, organizados e se utilizando do direito à participação popular, podem reivindicar acesso a canais de diálogo com o ente público?

Tais pontos exigem um mergulho profundo por parte das Ouvidorias para que, conscientes de sua competência e de seu compromisso com a plena cidadania e com os direitos da população, possam se aprofundar e agregar valor a suas ações cotidianas, gerando inovações significativas em sua gestão e na compreensão de sua função social. 


\section{REFERÊNCIAS}

ABI-EÇAB, Alice. Sobre a implantação do curso de Serviço Social na Universidade de São Paulo. 2015.155 f. Tese (Mestrado em Serviço Social) - Programa de Estudos Pós-Graduados em Serviço Social, Pontifícia Universidade Católica de São Paulo, São Paulo, 2015. Disponível em: <https://tede2.pucsp.br/handle/handle/17725>. Acesso em: 26 jun. 2019.

ABO-Associação Brasileira de Ouvidores/Ombudsman. Código de Ética dos Ouvidores/Ombudsman. Fortaleza, 1997, [s.p.]. Disponível em: <http://www.abonacional.org.br/codigo-de-etica>. Acesso em: 26 jun. 2019.

Decálogo do Ouvidor. São Paulo, [s.d.], [s.p.]. Disponível em: <http://www.abonacional.org.br/decalogo>.

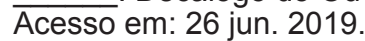

BRASIL. Constituição da República Federativa do Brasil, Brasília, DF: Senado, 1988. Disponível em: <http://www. planalto.gov.br/ccivil_03/constituicao/constituicaocompilado.htm>. Acesso em: 26 jun. 2019.

Lei 8.080 de 19 de setembro de 1990. Dispõe sobre as condições para a promoção, proteção e recuperação da saúde, a organização e o funcionamento dos serviços correspondentes e dá outras providências. Brasília, DF, 1990a. Disponível em: <http://www.planalto.gov.br/ccivil_03/leis/L8080.htm>. Acesso em: 26 jun. 2019.

Lei 8.142, de 28 de dezembro de 1990. Dispõe sobre a participação da comunidade na gestão do Sistema Único de Saúde (SUS) e sobre as transferências intergovernamentais de recursos financeiros na área da saúde e dá outras providências. Brasília, DF, 1990b. Disponível em: <http://www.planalto.gov.br/ccivil_03/leis/L8142.htm>. Acesso em: 26 jun. 2019.

BROWN, Theodore M.; CUETO, Marcos; FEE, Elizabeth. A transição de saúde pública 'internacional' para 'global' e a Organização Mundial da Saúde. Hist. Cienc. Saúde-Manguinhos, Rio de Janeiro, v. 13, n. 3, p. 623-647, set. 2006. Disponível em: <http://www.scielo.br/scielo.php?script=sci_arttext\&pid=S010459702006000300005\&Ing=en\&nrm=iso>. Acesso em: 26 jun. 2019.

CGU-Controladoria-Geral da União, Ouvidoria-Geral da União. Guia de orientação para a gestão de Ouvidorias. Brasília (DF), 2013. Disponível em: <http://www.cgu.gov.br/assuntos/ouvidoria/produtos-e-servicos/consulta-publica/ arquivos/produto_5_gestao_de_ouvidorias.pdf>. Acesso em: 26 jun. 2019.

CUETO, Marcos. Saúde Global: uma breve história. Rio de Janeiro: Editora Fiocruz, 2015.

DALLARI, Sueli Gandolfi. O direito à saúde. Rev. Saúde Pública, São Paulo, v. 22, n. 1, p. 57-63, fev. 1988. Disponível em: <http://www.scielosp.org/scielo.php?script=sci_arttext\&pid=S003489101988000100008\&lng=pt\&nrm=iso>. Acesso em: 26 jun. 2019.

FMUSP-Faculdade de Medicina da Universidade de São Paulo. Portal FMUSP. Rede Apoio ao Estudante. 2019. Disponível em: <http://fm.usp.br/rede-apoio/portal/>. Acesso em: 26 jun. 2019.

FORTES, Paulo Antônio de Carvalho; RIBEIRO, Helena. Saúde Global em tempos de globalização. Saúde Soc., São Paulo, v. 23, n. 2, p. 366-375, jun. 2014. Disponível em: <http://www.scielo.br/scielo.php?script=sci_arttext\&pi$\mathrm{d}=\mathrm{S} 010412902014000200366 \&$ Ing=en\&nrm=iso>. Acesso em: 26 jun. 2019.

JORNAL DA USP. USP sobe 23 posições e alcança a melhor classificação no QS Ranking. Assessoria de Imprensa da USP, Jornal da USP, Universidade, São Paulo [s.p.], 5 set. 2016a. Disponível em: <http://jornal.usp.br/universidade/usp-sobe-23-posicoes-e-alcanca-a-melhorclassificacao-no-qs-ranking/>. Acesso em: 26 jun. 2019.

USP é a latino-americana mais bem classificada no ranking Times Higher. Assessoria de Imprensa da USP, Jornal da USP, Universidade, São Paulo [s.p.], 21 set. 2016b. Disponível em: < http://jornal.usp.br/universidade/usp-e-a-latino-americana-mais-bem-classificadano-ranking-times-higher/>. Acesso em: 26 jun. 2019.

USP é considerada a melhor universidade pública do ano pelo Guia do Estudante. Assessoria de Imprensa da USP, Jornal da USP, Universidade, São Paulo [s.p.], 14 out. 2016c. Disponível em: <http://jornal.usp.br/universidade/usp-e-considerada-a-melhor-universidade-publicado-ano-pelo-guia-do-estudante/>. Acesso em: 26 jun. 2019.

Ranking CWU classifica USP entre as melhores do mundo em oito áreas. Assessoria de Imprensa da USP, Jornal da USP, Universidade, São Paulo [s.p.], 4 abr. 2017. Disponível em: <http://jornal.usp.br/universidade/ranking-saudita-classifica-usp-entre-as-melhoresdo-mundo-em-oito-areas/>. Acesso em: 26 jun. 2019.

Em mais um ranking, USP é considerada a melhor universidade brasileira. Assessoria de Imprensa da USP, $\overline{J o r n a l}$ da USP, Universidade, São Paulo [s.p.], 18 jun. 2019. Disponível em: <https://jornal.usp.br/institucional/em-mais-um-ranking-usp-e-considerada-a-melhor-universidade-brasileira/>. Acesso em: 26 jun. 2019. 
LEITE, Silvana Nair; VASCONCELLOS, Maria da Penha Costa. Construindo o campo da pesquisa: reflexões sobre a sociabilidade estabelecida entre pesquisador e seus informantes. Saúde soc., São Paulo, v. 16, n. 3, p. 169-177, dez. 2007. Disponível em: <http://www.scielo.br/scielo.php?script=sci_arttext\&pid=S010412902007000300016\&ln$\mathrm{g}=\mathrm{en} \& \mathrm{nrm}=\mathrm{iso}>$. Acesso em: 26 jun. 2019.

MINAYO, Maria Cecília de Souza. O desafio do conhecimento: pesquisa qualitativa em saúde. 7. ed. São Paulo: Hucitec; Rio de Janeiro: Abrasco, 2000.

MONTAÑO, Carlos. Pobreza, "questão social" e seu enfrentamento. Serv. Soc. Soc., São Paulo, n. 110, p. 270-287, jun. 2012. Disponível em: <http://www.scielo.br/scielo.php?script=sci_arttext\&pi$\mathrm{d}=\mathrm{S} 0101-66282012000200004 \&$ Ing=en\&nrm=iso $>$. Acesso em: 26 jun. 2019.

NETTO, José Paulo. Cinco notas a propósito da "questão social". Temporalis, Brasília: ABEPSS, Grafline, n. 3, p. 41-49, jan./jul. 2001.

; BRAZ, Marcelo. Economia política: uma introdução crítica. 3. ed. São Paulo: Cortez, 2007.

OMS. Constituição da Organização Mundial da Saúde. Biblioteca Virtual de Direitos Humanos da Universidade de São Paulo, 1946. Disponível em: <http://www.direitoshumanos.usp.br/index.php/OMS-Organiza\%C3\%A7\%C3\%A3oMundial-da-Sa\%C3\%BAde/constituicao-da-organizacao-mundial-da-saudeomswho.html>. Acesso em: 26 jun. 2019.

SANTOS, Josiane Soares. “Questão Social”: particularidades no Brasil. São Paulo: Cortez, 2012. 